\title{
La trascendencia de la campaña del "miedo" en las elecciones de 2004 y la propaganda del "peligro" en México en 2006
}

LaURi García DueÑas

RESUMEN

El objetivo de este ensayo es describir y narrar la forma en que la campaña del "miedo" realizada por ARENA en las pasadas elecciones presidenciales de El Salvador inclinó a su favor las preferencias electorales. Asimismo, pretendo destacar cómo esta particular forma de propaganda afectó los comicios presidenciales del 2 de julio en México.

\section{ABSTRACT}

The purpose of this article is describing how the campaign of "fear" launched by ARENA during the last presidential election in El Salvador influenced over the electoral preferences. This essay emphasizes how this particular sort of electoral propaganda affected the Mexican presidential election in July.

\section{Caracterización del "miedo" y el "peligro"}

"Un voto con miedo, es un voto sin libertad", fueron las palabras que el ahora fallecido Schafik Jorge Handal, candidato a la presidencia de El Salvador en 2004 por el Frente Farabundo Martí para la Liberación Nacional (FMLN) pronunció luego de aceptar su derrota ante el candidato Elías Antonio Saca, de la oficialista ARENA. 
Estas palabras pretendían hacer una acusación pública contra la estrategia política que el partido en el poder desde 1989 utilizó en su contra durante la última contienda presidencial.

"Reconocemos eso (la victoria de Saca) pero no lo felicitamos porque esta votación la consiguió ARENA con el método del miedo y eso es un atentado contra la democracia”, subrayó el histórico líder comunista.

El dirigente de izquierda se encontraba defendiendo una postura partidista, pero la llamada campaña del "miedo" — más allá de la crispación de la izquierda - fue, en la práctica, una realidad durante la antesala de las presidenciales.

En gruesas líneas podemos aseverar que la propaganda de ARENA contra su principal contrincante se basó en dos significativas suposiciones de las que quiso convencer a los votantes salvadoreños.

En primer lugar, si el FMLN lograba gobernar el país reproduciría una forma de gobierno similar a la de Cuba o Venezuela; en segundo, de ganar la izquierda, el gobierno de Estados Unidos adoptaría una política exterior en contra de los salvadoreños residentes en ese país y bloquearía el envío de las remesas familiares.

Semejantes acusaciones, de la mano con el calificativo de "terroristas", que ARENA le adjudica al FMLN, y que en un contexto mundial posterior al 11-S es, sin duda, algo sumamente grave; fueron repetidas hasta la saciedad en los diversos medios de comunicación social, aprovechando que en este país centroamericano el Tribunal Supremo Electoral (TSE) no regula la duración "al aire" de los distintos mensajes proselitistas. Asimismo, la derecha posee la simpatía de la mayoría de medios de comunicación de El Salvador, o por lo menos, de los grandes canales de televisión y periódicos.

Además, es importante considerar que las remesas familiares son el principal sostén de la economía salvadoreña. Solamente en 2003 ingresaron a este país de casi 7 millones de habitantes; 2.105,3 millones de dólares, en 2004 fueron 2.547,6 millones y el año pasado dicha ayuda familiar totalizó 2.830,2 millones de dólares.

El Banco Central de Reserva (BCR) de El Salvador registra un aumento en estos volúmenes de entrada de capital, año con año. Y es sabido que cada familia salvadoreña tiene por lo menos un pariente en Estados Unidos. 
Frente a lo anterior, la sola mención de que, de llegar al poder un gobierno diferente al ya instaurado por la derecha, el pilar de sostenimiento de muchas familias pudiese estar en riesgo, influyó en las consideraciones que hizo el votante salvadoreño antes de ejercer el sufragio.

Hay que subrayar que los gobiernos de ARENA han mantenido una política exterior favorable y hasta dependiente de los Estados Unidos. Algunos ejemplos: fue EE.UU. quien durante el conflicto armado (1980-1992) financió en gran medida la lucha "contrainsurgente"; El Salvador es el único país latinoamericano con tropas en Irak y el gobierno de George W. Bush ha otorgado a unos 230.000 salvadoreños un Estatus de Protección Temporal (TPS, por sus siglas en inglés) para que puedan trabajar legalmente en EE.UU. luego de los dos terremotos de 2001 registrados en El Salvador.

Más allá del apelativo de "terroristas" que ARENA le ha colocado al FMLN —adjetivo más abstracto y de difícil comprensión para los salvadoreños menos informados o con menor capital escolar- ARENA ha logrado dar en el blanco en las preocupaciones ciudadanas del país.

La campaña del "miedo" estuvo referida a un estratégico punto de interés de las familias salvadoreñas: las remesas. La acusación de que un posible gobierno del FMLN provocaría un obstáculo para el libre flujo de éstas y una política exterior adversa no fue desmentida por el embajador de EE.UU. en El Salvador, Douglas Barclay, sino hasta después que Elías Antonio Saca ganara la presidencia. El partido ARENA ganó los comicios de 2004 con 1,314,436 votos, mientras que el FMLN obtuvo 812,519. Con poco esfuerzo - pero distinguiendo los matices del caso-, se puede contemplar que en México se vivió un ambiente preelectoral similar al registrado en El Salvador.

Aunque no hay que olvidar que en las diferencias entre ambos países destacan que México recién inició su camino hacia la alternancia política luego que el Partido Revolucionario Institucional (PRI) fuera derrotado en el 2000 luego de más de setenta años en el poder. El PRI salió del Ejecutivo luego que muchos mexicanos decidieran apoyar con su "voto útil” al PAN, con tal de romper la prolongada sucesión de gobiernos priístas.

En El Salvador, la ex guerrilla del FMLN se incorporó a la vida política en 1992 tras los Acuerdos de Paz que concluyeron con una cruenta

\section{7}


guerra civil de doce años cuyo saldo fue 75.000 muertos, 12.000 lisiados y 8.000 desaparecidos, según organismos humanitarios.

En el seno de la sociedad mexicana ha surgido recientemente un movimiento llamado "La Otra Campaña", impulsado por el Ejército Zapatista de Liberación Nacional (EZLN) que pretende reavivar el movimiento social y alentar la participación ciudadana más allá de las elecciones presidenciales.

Julio de 2006 encuentra a El Salvador en medio de manifestaciones de calle organizadas por distintos movimientos sociales que protestan contra el alza del precio de los servicios básicos. Un hombre dispara con un $\mathrm{M}-16$ y en los enfrentamientos con la policía ocurre la muerte de dos policías.

Aunque ambos países latinoamericanos tienen obvias diferencias históricas-políticas; lo cierto es que también existen varias coincidencias.

En México, a unos pocos días de la celebración de las elecciones, las encuestas indicaban que los dos principales contendientes serían sin duda Andrés Manuel López Obrador del Partido de la Revolución Democrática (PRD) y Felipe Calderón del PAN.

Y aquí es donde surge la campaña del “peligro". El PAN, ante la popularidad del candidato perredista —obtenida luego de fungir como Jefe de Gobierno de la ciudad de México- optó por incluir en su propaganda la aseveración de que López Obrador significaba "un peligro para México".

En este sentido se incluía la suposición de que este líder podría tomar una línea de gobierno similar a la de Venezuela. Es más, el presidente Hugo Chávez se quejó de que su imagen haya sido utilizada para tratar de afectar negativamente a López Obrador:

"Caracas, 22/Marzo/2006.- Associated Press (AP) Chávez señaló, en una cadena de radio y televisión, que "la derecha mexicana (está) utilizando a través de la televisión una cuña... para tratar de frenar el ascenso de la izquierda mexicana y de su candidato presidencial Andrés Manuel López Obrador”.

El mandatario izquierdista añadió, durante una visita a una planta termoeléctrica en el estado centro costero de Carabobo, que la acción de la derecha mexicana contra su persona formaba parte de "campaña internacional” contra el gobierno venezolano. El canciller Alí Rodrí- 
guez denunció la semana pasada que existe una "campaña sostenida" promovida por la prensa y el gobierno de México contra Venezuela. Rodríguez hizo la declaración en alusión a una denuncia que apareció en un diario mexicano en la que se señaló que el gobierno venezolano estaría interfiriendo en la campaña electoral de México.

En un artículo publicado en El Universal el pasado 26 de mayo, el reconocido intelectual mexicano Carlos Monsiváis expresó, al respecto de los argumentos presentados por Acción Nacional:

“Asegura el candidato del PAN, Felipe Calderón: 'Seguiré diciendo que López Obrador es un peligro para México’. No extraña lo anterior en alguien que desconoce el valor de las palabras que, conviene avisarle, podrían formar conceptos relacionados con acciones atadas a consecuencias. ¿Cómo define Calderón "un peligro para México"? ¿Algo en la índole de "si AMLO gana, los ricos y las clases medias perderán sus propiedades, los anuncios de las videntes estipulan que ya comenzó la anexión a Venezuela, y que todavía arden los pozos petroleros en el sureste, incendiados por López Obrador”?

A tanto no se atreve don Felipe, aunque sí prodiga mentiras truculentas: el crecimiento de la deuda del gobierno de la ciudad de México, "la polarización" de la sociedad (asunto donde la iniciativa de la derecha es imbatible) y, muy especialmente, sus hipótesis de política-ficción. Ejemplo posible: en 2008, El Peje [apelativo con el que se conoce a López Obrador, N. del E.] nacionalizará la banca, la Universidad Anáhuac y, por error, las marchas de protesta.

AMLO, "un peligro para México", es la cima de la campaña de odio tan costosamente divulgada a través de la red, y tan deudora de los métodos del Partido Popular español y de los mercadólogos de la derecha estadounidense. Esto conlleva riesgos. Uno, irremediable, es volver orgánica la histeria revanchista; otro es adoptar para siempre el infantilismo de la promesa tan esencial en el pensamiento (sé lo que digo) de Fox.

El texto anterior pretende —no sin la ironía y la clara toma de posición de Monsiváis - explicar lo que subyace a la afirmación de que López Obrador es un "peligro" para México. Este estribillo posee sin duda, una carga ideológica y política similar a la que se le atribuyó a la figura

\section{9}


del candidato Schafik Handal en las elecciones de 2004 en El Salvador. Este representaba — para los estrategas de campaña de ARENA - una imagen propicia para trabajar en las agencias de publicidad y lograr que produjera "miedo": Ex comandante guerrillero, declarado comunista, Handal solía aparecer muy sonriente en las fotografías junto con Fidel Castro, Hugo Chávez y Evo Morales.

La imagen de López Obrador — con menos ventajas para sus contrincantes que las otorgadas por el ex candidato salvadoreño- fue tratada por el PAN también para que causase "miedo" a la población y los votantes llegasen a coincidir que sí constituía un peligro para ese país.

\section{El poder detrás de un estribillo}

Muchos teóricos de la comunicación han llegado a coincidir en el hecho de que los medios de comunicación influyen de alguna medida en los sujetos que se exponen a éstos. Si bien el grado de influencia constituye un punto de divergencia entre los teóricos, han quedado en el pasado fórmulas simplistas como la de la aguja hipodérmica que sostenía que la relación con los mass media no era negociada por los espectadores sino más bien constituía una influencia directa y determinante.

El sentido común ha llegado a la academia para que se concluya que un mensaje mediático es interpretado por los sujetos, dependiendo de su contexto socioeconómico e histórico, así como de otra serie de condiciones en las que están inmersos.

Así, la hipótesis de este ensayo es que a pesar que una campaña política a través de los medios de comunicación no determine por completo una elección presidencial, sí influye en la decisión de los votantes al referirse a temas de su interés y que pueden afectar su vida cotidiana.

En el caso de las campañas contra López Obrador y Handal, sus detractores se dirigieron a la emotividad de los votantes, repitiendo constantemente que ambos significaban un peligro para el sistema político y la forma cotidiana de vida de sus respectivos países.

\section{Tejiendo desventajas para el contrario}

El lingüista Oswald Ducrot en su teoría de los bloques semánticos sostiene que hay dos tipos de discurso: los encadenamientos denominados normativos y los encadenamientos denominados transgresores (Ducrot, 2004). A pesar que reconoce que en los discursos "es posible 
encontrar cualquier cosa encadenada con cualquier otra", entre los encadenamientos denominados normativos menciona ejemplos como 'la situación de Juan ha mejorado, está, por lo tanto, contento'. Como vemos, es una conclusión bastante lógica pensar que, si la situación de Juan ha mejorado, debe estar contento.

En el caso de la campaña del PAN contra López Obrador donde se afirma que éste "es un peligro para México", se podría aplicar la teoría de los bloques semánticos, atribuyendo al discurso tácito de sus detractores la lógica antes mencionada. "López Obrador es un peligro para México, por lo tanto no es adecuado votar por él", o bien: "El FMLN es terrorista, por lo tanto no es adecuado votar por ellos". De esta manera, el votante deduce la conclusión lógica implícita en el discurso, aunque esto no significa que vaya necesariamente a actuar conforme a ésta. Porque, como ya mencionamos, son muchos los factores que pueden estar implicados en la relación entre los mensajes emitidos por los medios de comunicación y la toma de decisión de los votantes. No obstante, hay que destacar que en el entretejido de esta relación pueden llegar a surtir mayores efectos los mensajes de contenido emotivo:

Las pruebas experimentales no aclaran suficientemente la mayor o menor eficacia de los mensajes de tipo racional o emocional, haciéndola depender de las relaciones entre comunicación y tipo de auditorio. Los autores se inclinan por una mayor eficacia persuasiva de los mensajes con contenido afectivo, porque producen mayores incentivos al receptor, despiertan en mayor grado la atención, activan las motivaciones y predisponen al sujeto a las conclusiones deseadas en el mensaje (Monzón, 1990).

La conclusión que desean causar en la opinión pública el PAN y ARENA es que no resulta conveniente cambiar de forma de Gobierno ni mucho menos elegir como alternativa a una izquierda "peligrosa". En este punto es importante detenernos para preguntarnos: ¿qué es la opinión pública? ¿A qué se refiere este concepto, tan utilizado en los medios de comunicación y aceptado en la vida diaria como un término con significados distintos? Para Giovanni Sartori, "el público en cuestión es sobre todo un público de ciudadanos, un público que tiene una opinión sobre la gestión de los asuntos públicos, y por lo tanto, sobre los asuntos de la ciudad política. En síntesis: el público no es solo el sujeto, sino también el límite de la expresión. Una opinión se denomina pública no sólo porque es del público (difundida entre muchos, o entre

\section{1}


los más), sino también porque afecta a objetos y materias que son de naturaleza pública: el interés general, el bien común, y en esencia, la res pública” (Sartori, 1992).

Norberto Bobbio introduce una segunda acepción para el concepto, subrayando el hecho de que muchas veces la opinión pública se convierte en patrimonio de unos pocos: "La opinión pública se ve como un componente del sistema político, una fuerza: es la opinión de los grupos que cuentan, un reducido grupo de aristócratas e intelectuales en los regímenes absolutistas, las clases emancipadas en los sistemas democráticos con sufragio restringido, los jerarcas de partido en los modernos sistemas dictatoriales, etcétera, etcétera. Este doble significado supone la existencia de distintos tipos de público” (Bobbio, 2001).

Así, el mensaje enviado por el PAN y ARENA a través de los medios de comunicación se diluye en un público con distintas motivaciones y que obtiene gratificaciones diferentes, según explica la teoría de los usos y las gratificaciones. La idea de que la audiencia traslada a los medios sus propias necesidades, dependiendo de su personalidad y sus circunstancias sociales, nos hace también reflexionar que no podemos concluir que "el efecto" de los mensajes mediáticos es categórico y unidireccional. Claro que la amenaza del supuesto "peligro" que podrían significar gobiernos de izquierda hace mayor mella en aquellos grupos cuyas circunstancias sociales dependen precisamente, en el caso de El Salvador, de una ayuda externa de sus familiares en Estados Unidos y que fue uno de los puntos que la publicidad de ARENA aprovechó para tomar ventaja.

En el caso de México, el mensaje de "peligro" pudo resultar más agradable para aquellos grupos conservadores de derecha que encuentran una gratificación a su ideología o bien hizo más eco en aquellos grupos con menor capital escolar.

Ahora bien, hay que tomar en cuenta dos conceptos importantes que pueden clarificar la forma en que los electores toman sus decisiones a la hora de votar: el modelo de inercia y circunstancia de la encuestadora mexicana María de las Heras. Esta autora reconoce que en México pasaron décadas de primacía del PRI en las cuales no fueron necesarias las encuestas de opinión para medir posibles tendencias electorales porque ya se conocía cual partido sería el ganador. Sin embargo, en los últimos años se vuelven necesarias y para esto hay que tener en cuenta dos tipos 
de votantes: Los inerciales, o también conocidos como el "voto duro" y los circunstanciales, que pueden tomar su decisión a partir de sucesos y campañas mediáticas propios de la coyuntura (Heras, 1999). Es a este segundo grupo al que pueden afectar en mayor medida las campañas del "miedo" y el "peligro", ya que el voto duro (aunque estancado en su crecimiento debido a la crisis de los partidos políticos) no suele cambiar de opinión aún ante este tipo de acusaciones. Los "duros", son aquellos que están totalmente decididos a votar por el partido, muchas veces independientemente del candidato y las circunstancias.

El psicólogo Angus Campell, en un estudio realizado en Estados Unidos en 1964, nos proporciona algunas luces sobre otros aspectos que intervienen en la decisión electoral: a) la identidad político partidaria b) la imagen de los candidatos y c) los temas de interés de las campañas políticas (Kuschick, 2004). En el caso de El Salvador, la campaña del "miedo" fue dirigida a dañar la imagen del candidato Handal y a sacar a flote temas de enorme interés como las remesas. Mientras, en México, el PAN además de intentar perjudicar la imagen de López Obrador, en la que estaba montada la campaña del PRD durante la contienda electoral, pretendió ganar adeptos que estuviesen en contra del endeudamiento del Gobierno mexicano y una posible unión estratégica con Venezuela.

Pero antes de que la maquinaria publicitaria del PAN pusiera énfasis en el endeudamiento del gobierno de la ciudad de México — adjudicada a López Obrador-, ¿quién se preguntaba por este tema? Si bien los medios de comunicación no nos dicen quépensar, sí nos dicen sobre qué pensar, tal como lo sostiene la teoría de la fijación de agenda. El candidato del PRD se defiende aduciendo que el porcentaje de incremento de la deuda con respecto al anterior gobierno de la ciudad es mínimo, alrededor de un 10 por ciento. Sin embargo, como bien dice María de las Heras, ante la franca disminución de los votos inerciales, y tal como lo registra Campell, la imagen - tanto de López Obrador, como en su momento la de Handal- y la percepción que tengan de ésta los votantes pueden marcar la diferencia en el juego político.

Retomando el concepto de percepción hay que considerar que nos comparamos con otros y con las opiniones de otros, porque la actitud social no se da en el aislamiento."Nuestras percepciones no están formadas simplemente por la combinación de nuestra inteligencia innata, nuestra personalidad única y nuestros sentidos, sino sobre todo por el contacto con los otros” (Glynn, 1999).

\section{3}


La socialización política depende así de la ideología y las preferencias políticas pero también influye el papel de los padres. "Hay una posibilidad de que la ideología se mantenga con nosotros" (Ídem, 1999).

En el caso de los escenarios políticos aquí analizados, podemos decir que además de lo emotivo - factor destacado desde el inicio de este ensayo-, la decisión de los electores depende de sus percepciones particulares ante la campaña del "miedo" y el "peligro", pero sobre todo de estas percepciones puestas en relación con las de sus conocidos, amigos o colegas. Las reglas de decisión están basadas además en los diferentes razonamientos de las personas; diferentes, dependiendo de los contextos y roles (Aguilar, 1987). No necesariamente deciden de la misma forma dos personas de distinta clase social o profesión. Cada una posee sus propios intereses.

La teoria de la espiral del silencio presenta además la posibilidad de que la gente tema expresar su opinión y se pliegue a la de una supuesta mayoría. Si el elector, alentado por los medios de comunicación, llega a creer que "la mayoría" piensa que López Obrador es "un peligro para México" y el FMLN es "terrorista” puede llegar a la conclusión lógica (basada en la teoría de Ducrot) de que no es conveniente votar por ellos.

\section{Posibles consecuencias de las campañas de miedo y peligro}

En El Salvador, fue clara - tal como lo ratifico el mismo Handal_ la influencia que la campaña del miedo causó sobre la izquierda. Tanto así que el candidato del FMLN recordó la importancia de la estrategia de ARENA a la hora de reconocer su derrota, no sin antes dejar en el tintero que un voto empujado por el "miedo" no es lo más deseable para la sociedad democrática.

Por su parte, el presidente Saca, al conocer que el partido oficial había ganado nuevamente el Ejecutivo dijo: "Han tomado una decisión: han decidido convertirme en su presidente en primera vuelta". "A todos los salvadoreños, a mis hermanos salvadoreños, imuchas gracias!... Gracias por acudir al llamado de la patria, gracias por salvar a este país, gracias por esta manifestación en las calles”, agregó.

Si seguimos la teoría de los bloques semánticos, podríamos decir que en la frase de Saca se encontraba guardado un implícito "Gracias por salvar a este país del FMLN que representa un peligro para El Salvador". 
Sin embargo, debe quedar claro que no podemos adjudicar únicamente la victoria de Saca a la efectividad de la campaña del "miedo" realizada en contra de su histórico opositor, pues, como hemos visto en este ensayo, hay múltiples aspectos que influyen en la opinión pública y en la decisión de los electores. Además hay que reconocer que la victoria de la derecha en El Salvador descansa, entre otros factores, en la imagen - potenciada en los medios- del presidente Saca, la crisis interna del FMLN, la incapacidad de la izquierda de articularse con el movimiento social para ganar el apoyo popular y la campaña proselitista realizada por ARENA impulsada con millonarios fondos propiciando así una omnipresencia mediática.

En el caso de México, la hipótesis de que la campaña de "peligro" ha influido en los electores puede ejemplificarse con el hecho de que López Obrador, que se mantuvo arriba en las encuestas durante meses, empató técnicamente en un 35 por ciento de las preferencias con $\mathrm{Fe}$ lipe Calderón unos días antes de las elecciones. Su popularidad sufrió un significativo descenso en las últimas semanas, o por lo menos así lo registraron los sondeos.

Las mismas agencias internacionales de noticias reconocieron en sus reportes la importancia que tuvo la campaña "en detrimento" de López Obrador sin dejar de recalcar que se perpetró una batalla de descalificaciones entre ambos partidos, el PAN y el PRD. El 2 de julio, el Instituto Federal Electoral (IFE) no pudo declarar un claro ganador ante lo reñido de la contienda.

Pero tres días después, y con ligera ventaja, se conoció que Calderón ganó las elecciones. López Obrador, no obstante, se declaró inconforme con el resultado y aseguró que se cometió un fraude en su contra. En los comicios del 2 de julio, se registraron 41 millones 791 mil 132 votos, de los cuales 15 millones 284 fueron para Calderón (35.89\%), 14 millones 756 mil 350 para Andrés Manuel López Obrador (35.31\%) y 9 millones 301 mil 441 (22.26\%) para Roberto Madrazo, del PRI. La diferencia entre Calderón y Obrador: apenas $0.58 \%$.

\section{Emotividad y campañas. Conclusión}

Durante el presente ensayo se han descrito algunas de las teorías que explican los factores que pueden propiciar cambios en la opinión pública, así como algunos aspectos que influyen en los electores para

\section{5}


inclinarse hacia alguno $u$ otro partido en medio de campañas proselitistas como la de "miedo" en El Salvador y la de "peligro" en México. Hemos visto cómo los aspectos emotivos son claves en este proceso de toma de decisiones, sin descartar aquellos condicionantes racionales, en busca de gratificaciones, culturales, sociales e ideológicos/inerciales.

Los grupos interesados en desacreditar a sus oponentes, tales como ARENA y el PAN — tomando en cuenta que muchas veces los partidos atacados no se quedan atrás e intentan defenderse en un similar lenguaje de acerbas acusaciones - hacen uso de un lenguaje confrontativo particular, reforzado por las características propias del nuevo ágora: los medios de comunicación.

Hay que tener en cuenta entonces que "los grupos interesados en afectar la opinión pública sólo pueden pasar del poder social al poder político si hacen propaganda a favor de sus intereses en un lenguaje capaz de movilizar convicciones" (Habermas, 1998). Y, sin duda, la meta proselitista de ARENA y el PAN es movilizar convicciones y evitar perder el control del Gobierno y el Estado. En este punto, cobra vigencia la frase emblemática de Maquiavelo: “el fin justifica los medios”. En este caso, los medios utilizados son los de comunicación y una campaña totalmente emotiva, basada en adjetivos peyorativos y descalificaciones.

Tanto en México como en El Salvador, esta "guerra sucia”, como la llaman muchos analistas, sin ser necesariamente la protagonista central de una pugna política donde están en juego intereses y algo más que imágenes, ha sido un aspecto, aunque coyuntural, condicionante de nuevos escenarios de decisión política. Podríamos recordar los argumentos de Heras para cuestionar el hecho de que los partidos estén, cada vez más, intentando convencer a los votantes circunstanciales que son influidos por la coyuntura y la propaganda. Estos partidos, enfrascados en una constante lucha verbal y de graves acusaciones, han descuidado el trabajo partidario, el contacto con la base y, por supuesto, las propuestas programáticas.

El "miedo" y el "peligro" se han vuelto estrategias mediáticas que están desviando a los partidos políticos de su obligación primigenia: la búsqueda del bien común y la atención a la res pública. 
-Aguilar Villanueva, Luis, 1987, "Una reconstrucción del concepto de Opinión Pública”, en la Revista Mexicana de Ciencias Políticas y Sociales, México, Centro de Documentación de la Facultad de Ciencias Políticas y Sociales de la Universidad Nacional Autónoma de México (UNAM).

-Bobbio, Norberto, 2001, Diccionario de Política Duodécimo edición, México, Siglo XXI.

-Bourdieu, Pierre, 1961. La distinción. Criterio y bases sociales del gusto. Madrid, Taurus.

-Ducrot, Oswald, 2004, "Sentido y argumentación" en Homenaje a Oswald Ducrot, Argentina, Editorial Universitaria de Buenos Aires.

-Glynn, Carroll, Susan Herbst, Garrett Keefe, 1999, Public Opinion, Washington, Westview Press.

-Habermas, Jürgen, 1998, Facticidad y validez, Madrid, Editorial Trotta.

-Heras, María de las, 1999, Uso y abuso de las encuestas, Elección 2000: Los Escenarios, México, Océano.

—Kuschick, Murilo, 2004, "Teorías del comportamiento electoral y algunas de sus aplicaciones" en Revista Mexicana de Ciencias Políticas y Sociales, México, Centro de Documentación de la Facultad de Ciencias Políticas y Sociales de la Universidad Nacional Autónoma de México (UNAM).

-Monzón, Cándido, 1990, La opinión pública, Madrid, Tecnos.

-Sartori, Giovanni, 1992, Elementos de teoría política, Madrid, Alianza.

\section{7}

